\title{
Erratum to: Surgical management of primary spinal hemangiopericytomas: an institutional case series and review of the literature
}

\author{
Ali Shirzadi - Doniel Drazin • Marcus Gates • Neda Shirzadi • \\ Serguei Bannykh · Xuemo Fan · Leonel Hunt · Eli M. Baron • \\ Wesley A. King $\cdot$ Terrence T. Kim $\cdot$ J. P. Johnson
}

Accepted: 10 January 2013/Published online: 25 January 2013

(c) Springer-Verlag Berlin Heidelberg 2013

\section{Erratum to: Eur Spine J}

DOI 10.1007/s00586-012-2626-z

There were errors in two author names of the article

The correct names are:

J. P. Johnson and Serguei Bannykh

The online version of the original article can be found under doi:10.1007/s00586-012-2626-z.

\footnotetext{
A. Shirzadi · D. Drazin · M. Gates · N. Shirzadi ·

E. M. Baron · J. P. Johnson $(\bowtie)$

Department of Neurosurgery, Cedars-Sinai Medical Center,

Los Angeles, CA, USA

e-mail: Spineexperts@aol.com

D. Drazin

e-mail: doniel.drazin@cshs.org

S. Bannykh $\cdot$ X. Fan

Department of Pathology and Laboratory Medicine,

Cedars-Sinai Medical Center, Los Angeles, CA, USA

L. Hunt - E. M. Baron - W. A. King - T. T. Kim - J. P. Johnson Spine Center, Cedars-Sinai Medical Center,

Los Angeles, CA 90048, USA
} 